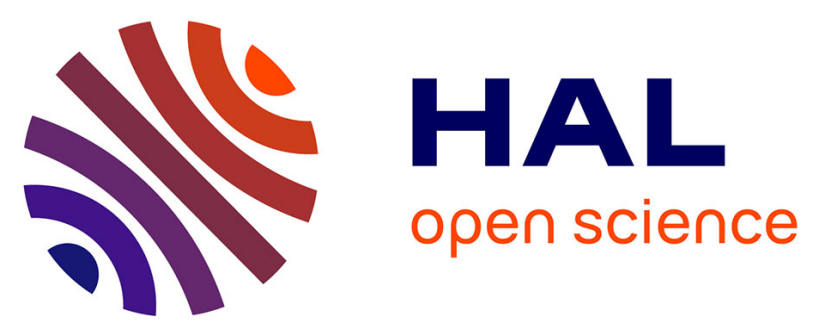

\title{
LOKALISATION DER GENE FÜR \\ PHOSPHORGLYCERAT-KINASE, GLUCOSE-6-PHOSPHAT-DEHYDROGENASE UND HYPOXANTHINGU ANINPHOSHORIBOSYL TRANSFERASE BEI RIND UND SCHWEIN MITTELS RIND-MAUS- UND SCHWEIN-MAUS-ZELLHYBRIDEN
}

\author{
M. Förstern
}

To cite this version:

M. Förstern. LOKALISATION DER GENE FÜR PHOSPHORGLYCERAT-KINASE, GLUCOSE6-PHOSPHAT-DEHYDROGENASE UND HYPOXANTHINGU ANINPHOSHORIBOSYL TRANSFERASE BEI RIND UND SCHWEIN MITTELS RIND-MAUS- UND SCHWEIN-MAUSZELLHYBRIDEN. Annales de génétique et de sélection animale, 1980, 12 (4), pp.421-421. hal00893307

\section{HAL Id: hal-00893307 https://hal.science/hal-00893307}

Submitted on 1 Jan 1980

HAL is a multi-disciplinary open access archive for the deposit and dissemination of scientific research documents, whether they are published or not. The documents may come from teaching and research institutions in France or abroad, or from public or private research centers.
L'archive ouverte pluridisciplinaire HAL, est destinée au dépôt et à la diffusion de documents scientifiques de niveau recherche, publiés ou non, émanant des établissements d'enseignement et de recherche français ou étrangers, des laboratoires publics ou privés. 
STUDIES ON THE VARIABIITTY AND HERITABITTY

OF THE MITOGENIC RESPONSE OF CATTIE I,YMPHOCYTES TOWARDS PLANT I,ECTINS

\title{
H. BUSCHMANN, J. MEYER and G. ENTRINGER
}

The variability of the response of cattle lymphocytes to the mitogens PHA and Con $A$ was tested in a dairy herd. Significant individual differences and variations due to the age of the animals appeared. Genetic differences in the response exist.

ZUSAMMENHANG ZWISCHEN HAEMOGLOBINTYP, SPURENELEMENTENVERSORGUNG

UND FORTPFIANZUNGSIEISTUNG BEI DEN MUT'TRSCHALEN DER UNGARISCHEN MERINORASSE

\section{FÉSÜS}

Forschungszentrum für Tievzucht und Tievernährung, Forschungsinstitut für Tievzucht, Hevceghalom, Ungarn

Verfasser fand im grossen Masstab signifikante Abweichung in einem Schafbestand bei der Nachkommenschatf in der Anzahl der erwarteten und gefundenen Haemoglobintypen. Viel weniger Lämmer des Typs HbAA und $\mathrm{HbAB}$ und viel mehr des Typs $\mathrm{HbBB}$ sind geboren. Die Fortpflanzung der Mutterschafe der einzelnen Haemoglobintypen war auch abweichend. Die Mutterschafe des HbAA-Type ergaben signifikant weniger Lämmer, als die der HbAB und HbBB-Typen.

Der untersuchte Schafbestand weider auf einer Fläche, die bekannt kupferarm ist und das verfütterte Kraftfutter und Massenfutter stammt auch aus dieser Fläche.

Der Verfasser hat mittels Untersuchung der Weidegras- und Ergänzungsfutterzusammensetzung nachgewiesen, dass die Kupferversorgung der Schafe nicht befriedigend war.

Im Blut und Wolle der Mutterschafe von HbAA-Type war weniger Kupfer nachzuweisen ( $1.09 \mathrm{mg} /$ I $00 \mathrm{ml}$, bez. $4.7 \mathrm{mg} / \mathrm{kg}$ ), als bei den Schafen der HbAB und HbBB-Typen. Er konnte aber keinen Zusammenhang zwischen erhaltenen Kupferkonzentrationswerten und Fortpflanzungsleistung der Mutterschafe feststellen.

Weitere Untersuchungen sind notwendig im entscheiden zu können, ob die mangelhafte Kupferversorgung für die im Bestand festgestellten Abweichungen verantwortlich ist.

LOKALISATION DER GENE IÜ̈R PHOSPHORGLYCERAT-KINASE, GLUCOSE-6-PHOSPHAT-DEHYDROGENASE UND FIYPOXANTHINGUANINPHOSHORIBOSYLTRANSFERASE BEI RIND UND SCHWEIN MITTELS RIND-MAUS- UND SCHWEIN-MAUS-ZELLHYBRIDEN

\author{
M. FÖRSTERN \\ Lehrstuhl für Tierzucht der Technischen, Universität München, \\ D-8050 Freising-Weihenstephan
}

Rind-Maus- und Schwein-Maus-Zellhybriden wurden mittels PEG hergestellt. In diesen Hybridzellen verlieren sich zufällig die Rinderoder Schweinechromosomen nicht aber die Mauschromosomen. Diese Chromosomensegregation wird für in Genlokalisation in der Weise ausgenüzt, daß analysiert wird, welche Enzymmarker von Rind oder Schwein parallel mit bestimmten Chromosomen verbleiben und damit diesen zugeordnet werden könnten. Vorerst konnte beim Rind die Gene für G6PD, HGPRT und PGK und beim Schwein die für G6PD und HGPRT jeweils dem X-Chromosom zugeordnet werden. 